\title{
Global distribution of tropospheric ozone from satellite measurements using the empirically corrected tropospheric ozone residual technique: Identification of the regional aspects of air pollution
}

\author{
J. Fishman ${ }^{1}$, A. E. Wozniak ${ }^{1,2,3}$, and J. K. Creilson ${ }^{1,2}$ \\ ${ }^{1}$ Atmospheric Sciences Research, NASA Langley Research Center, Hampton, Virginia \\ ${ }^{2}$ Science Applications International Corporation (SAIC), Hampton, Virginia \\ ${ }^{3}$ Currently at Department of Meteorology, University of Maryland, College Park, Maryland
}

Received: 30 January 2003 - Published in Atmos. Chem. Phys. Discuss.: 17 March 2003

Revised: 30 May 2003 - Accepted: 24 June 2003 - Published: 2 July 2003

\begin{abstract}
Using coincident observations of total ozone from the Total Ozone Mapping Spectrometer (TOMS) and stratospheric ozone profiles from the Solar Backscattered Ultraviolet (SBUV) instruments, detailed maps of tropospheric ozone have been derived on a daily basis over a time period spanning more than two decades. The resultant climatological seasonal depictions of the tropospheric ozone residual (TOR) show much more detail than an earlier analysis that had used coincident TOMS and Stratospheric Aerosol and Gas Experiment (SAGE) ozone profiles, although there are many similarities between the TOMS/SAGE TOR and the TOMS/SBUV TOR climatologies. In particular, both TOR seasonal depictions show large enhancements in the southern tropics and subtropics in austral spring and at northern temperate latitudes during the summer. The much greater detail in this new data set clearly defines the regional aspect of tropospheric ozone pollution in northeastern India, eastern United States, eastern China, and west and southern Africa. Being able to define monthly climatologies for each year of the data record provides enough temporal resolution to illustrate significant interannual variability in some of these regions.
\end{abstract}

\section{Introduction}

Over the past several years, a number of studies have used information from the Total Ozone Mapping Spectrometer (TOMS) instrument to glean insight into the distribution of tropospheric ozone and the processes that influence its budget (e.g., Fishman et al., 1990; Kim and Newchurch, 1996; 1998; Hudson and Thompson, 1998; Ziemke et al., 1998;
2000; Fishman and Balok, 1999; Thompson et al., 2003). The primary challenge in each of these studies is the separation of the relatively small tropospheric component, generally 5 to $15 \%$, from the total column and then validating the resultant product against existing data sets, usually derived from ozonesonde measurements. For the most part, only a small fraction of TOMS total ozone measurements are used and the derived measurements have generally shown good agreement with available validation data sets.

In the current study, we have taken a different approach using as many TOMS measurements as possible to derive a tropospheric product. In simplest terms, we construct a daily global distribution of the stratospheric component of the total ozone field which should contain only large-scale structure. Next, we use gridded TOMS data at a resolution of $1^{\circ}$ latitude by $1.25^{\circ}$ longitude to examine a tropospheric product with equivalent resolution. The stratospheric column ozone (SCO) is derived from measurements from Solar Backscattered Ultraviolet (SBUV) instruments because they provide the best spatial resolution with enough frequency that relatively good global coverage can be obtained. In the tropics, the subtropics most of the time, and at middle latitudes during the summer and autumn seasons, the distribution of ozone in the stratosphere is invariant enough that observations over five days are generally representative of an average distribution over that 5-day period. Using this methodology, we have produced daily tropospheric ozone residual (TOR) maps between $50^{\circ} \mathrm{N}$ and $50^{\circ} \mathrm{S}$ from 1979 to 2000 . A gap exists in this dataset as no TOMS satellite operated between May 1993 and July 1996 and the aerosol index needed for one of the corrections we apply is not available between $\mathrm{Au}$ gust 1996 and July 1997.

Correspondence to: J. Fishman

(jack.fishman@nasa.gov)

(c) European Geosciences Union 2003 
In an earlier study, Fishman et al. (1990) presented the first climatology of tropospheric ozone derived from the TOR technique using the difference between TOMS total ozone and the SCO by subtracting the SCO determined from SAGE (Stratospheric Aerosol and Gas Experiment) and SAGE II measurements. The relatively infrequent SAGE profiles (normally $\sim 30$ per day) allowed only for the calculation of climatological seasonal (Fishman et al., 1990) or bimonthly (Fishman et al., 1991) distributions. From these studies, enhanced TOR values were found during the Northern Hemisphere $(\mathrm{NH})$ summers and over the tropical South Atlantic Ocean during austral spring. Although there are many similarities between the climatological TOMS/SAGE TOR and the TOMS/SBUV TOR, there are likewise some important differences that come to the fore because the data set available using the current methodology is much richer. Some of the more interesting regions include northeastern India, eastern United States, eastern China, and west and southern Africa.

As examples of the kinds of studies that can be performed with this new data set, we show that the high spatial resolution of the data can provide new insights into the vertical distribution of ozone over relatively pristine regions where altitude variations are easily quantified (Jiang and Yung, 1996; Kim and Newchurch, 1998; Newchurch et al., 2001). We also demonstrate how the TOR relates to the observed distribution of ozone at the surface during an air pollution episode. Lastly, we show how these data correlate to the population distribution over densely populated areas in India and China.

For the most part, TOMS total ozone data (http://toms. gsfc.nasa.gov/ozone/ozone.html) have primarily been used for global- or quasi-hemispheric-scale studies. The primary purpose of this paper is to demonstrate the regional utility of a new global tropospheric ozone database (http://asd-www. larc.nasa.gov/TOR/data.html) derived from the total ozone archive. The examples we present illustrate only a small fraction of studies that can be conducted in the forthcoming years by the scientific community as this data set is utilized.

\section{Data}

\subsection{TOMS Total Ozone Measurements}

TOMS total ozone measurements have been available from several satellites since November 1978 (see http://toms.gsfc. nasa.gov). Nimbus-7 operated from November 1978 through April 1993; the Earth Probe satellite operated at a relatively low orbit of $540 \mathrm{~km}$ and provided higher spatial resolution from July 1996 through December 1997 and then was boosted to a higher orbit of $740 \mathrm{~km}$ to obtain complete global coverage. For the current study, Nimbus-7 TOMS data (Version 7) from 1979 through 1993 and Earth Probe data from 1997 through 2000 have been analyzed. Only data from the Nimbus-7 and Earth Probe have been used in this study to take advantage of the availability of the aerosol index information that is part of the correction we apply to the measurements (Torres and Bhartia, 1999). In early 2001, it was discovered that the TOMS aboard the Earth Probe satellite was experiencing instrument problems and the quality of the total ozone measurements had degraded.

Known data anomalies in the total ozone measurements include a significant cross track bias and, unrelated to the instrument problems, the presence of tropospheric aerosols. A Fast Fourier Transform (FFT) routine is applied to the daily gridded TOMS fields to reduce the cross track bias that appears in the data fields as a wave number 14 due to orbital equator crossings. The presence of tropospheric aerosols is determined by the aerosol index data fields and is corrected in the total ozone measurements using the method described by Torres and Bhartia (1999). Summaries of the TOMS instrumental and operational characteristics and ozone data products can be found in Heath et al. (1975) and McPeters et al. (1993; 1996).

\subsection{SBUV Ozone Profiles and the Empirical Correction}

Vertical ozone profiles, as well as total ozone measurements, have been derived from measurements made by the backscattered ultraviolet technique since 1970 when the BUV instrument was launched on Nimbus-4 (Heath et al., 1975). A modified version of that instrument, the SBUV, was launched in October 1978 on the Nimbus-7 spacecraft by NASA and was operational until June 1990 (see http://nssdc.gsfc.nasa. gov/earth/Nimbus.html). Several subsequent launches of a second generation SBUV instrument, the SBUV/2, have been made by the National Oceanic and Atmospheric Administration (NOAA) on the NOAA-9, NOAA-11, and NOAA-14 satellites launched in 1984, 1988, and 1994, respectively.

The SBUV and SBUV/2 instruments rely on BUV radiance measurements at 12 wavelengths to derive total ozone and vertical ozone profiles. The nadir-looking SBUV instruments complete 14 orbits per day, with a revisit time of approximately 5 days. In this study we use data records from the 1979 through 1990 SBUV archive and from the 1989 through 2000 SBUV/2 archive. The ozone profile data are archived as 12 Umkher layer amounts in Dobson Units (DU) as seen in Fishman and Balok (1999). The SBUV data were processed by using the Version 6.0 algorithm; SBUV/2 data were processed with a Version 6.1 algorithm to implement a calibration correction specific to the NOAA-11 SBUV/2 instrument. A description of the Version 6 processing algorithm can be found in Bhartia et al. (1996). SBUV and SBUV/2 data sets are available from the NOAA National Environmental Satellite, Data, and Information Service (see http://orbit-net.nesdis.noaa.gov/crad/sit/ozone). For convenience, references made in this study to the SBUV data set apply to the combined SBUV and SBUV/2 data sets.

The integrated amount of ozone in the stratosphere is determined from SBUV profiles integrated from the tropopause 


\section{Seasonal Depictions of Climatological Tropospheric Ozone Residual (TOR) 1979-2000}

SBUV Tropospheric Ozone Residual (TOR) DJF 1979-2000

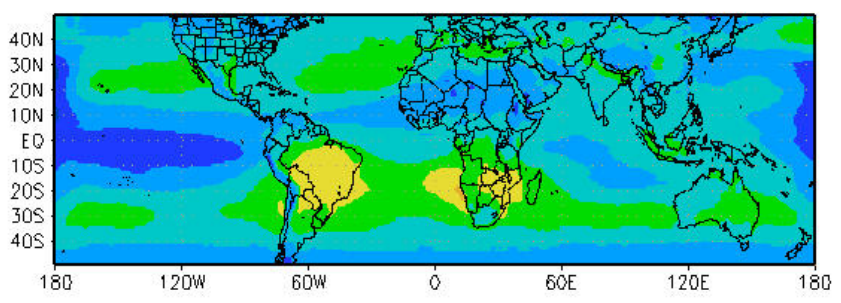

SBUV Tropospheric Ozone Residual (TOR) JJA 1979-2000

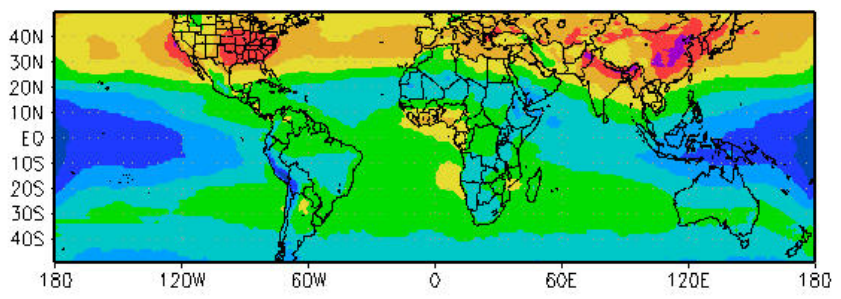

SBUV Tropospheric Ozone Residual (TOR) MAM 1979-2000

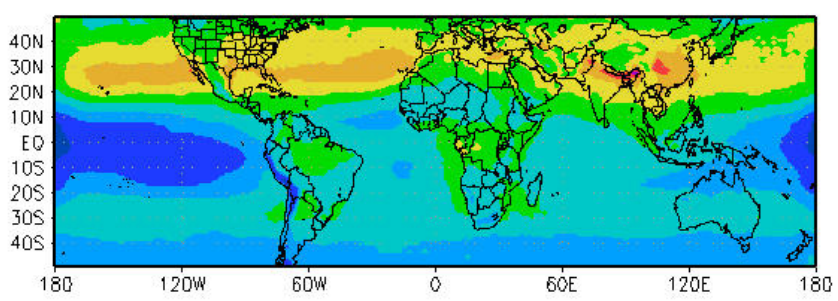

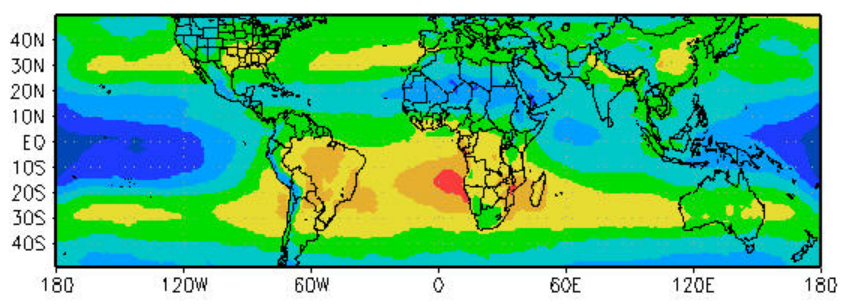

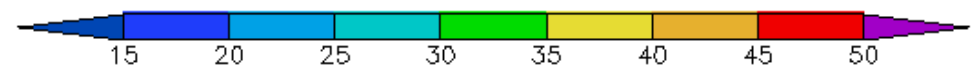

Fig. 1. Climatological depiction of tropospheric ozone residual obtained from the empirical correction technique using all available TOMS and SBUV measurements between 1979 and 2000. The four panels correspond to NH winter (DJF: December-January-February), spring (MAM: March-April-May), summer (JJA: June-July-August), and autumn (SON: September-October-November). Units on the color bar are Dobson Units (DU).

to the top of the atmosphere. Before integration above the tropopause, each SBUV profile is empirically corrected so that the amount of ozone below the tropopause is set equal to the monthly climatological amount determined from the Logan (1999) analysis. This quantity is then subtracted from the SBUV total ozone column to derive the stratospheric component (Fishman and Balok, 1999). That value (i.e., the integrated ozone amount above the tropopause derived from the SBUV measurement) is then used as input to derive a stratospheric ozone field using other such measurements over a five-day period to determine the field for the central day. That quantity is then subtracted from the concurrent TOMS total ozone amount to calculate the TOR for this study. Tropopause height information for the current study uses gridded $\left(2.5^{\circ}\right.$ latitude by $2.5^{\circ}$ longitude $)$ analyses provided by the National Centers for Environmental Prediction (NCEP). These analyses are produced every six hours and the value closest to the time of the SBUV observation is used in the current study (Kalnay et al., 1996).

For the discussion presented in the following sections, we present monthly maps that have been derived from the TOR distribution calculated daily and then averaged over the month. Thus, each $1^{\circ}$ latitude by $1.25^{\circ}$ longitude pixel shown in each seasonal climatology is an average of $\sim 1600$ points ( $\sim 90$ days $\times \sim 18$ years). For comparison, the seasonal climatologies described in Fishman et al. (1990) and Fishman and Brackett (1997) were derived by binning the individual TOR values derived from TOMS/SAGE into $5^{\circ}$ latitude by $10^{\circ}$ longitude boxes over $\sim 7$ years of observations; the result was $\sim 13$ data points per each box and each box consisted of an area 40 times the resolution of the present study. From such a data density, more than half the $1^{\circ}$ latitude by $1.25^{\circ}$ longitude boxes would contain no data.

\section{Results}

\subsection{Climatological Distribution}

A considerable effort has been ongoing to ensure consistency in the use of different satellite instruments to measure ozone (WMO, 1998). As different versions of satellite data sets are released, retrieved total ozone amounts are modified to take into account certain measurement artifacts that may not have been identified previously. Depending on what release 


\section{SAGE Tropospheric Ozone Residual (TOR) JJA 1979-91}

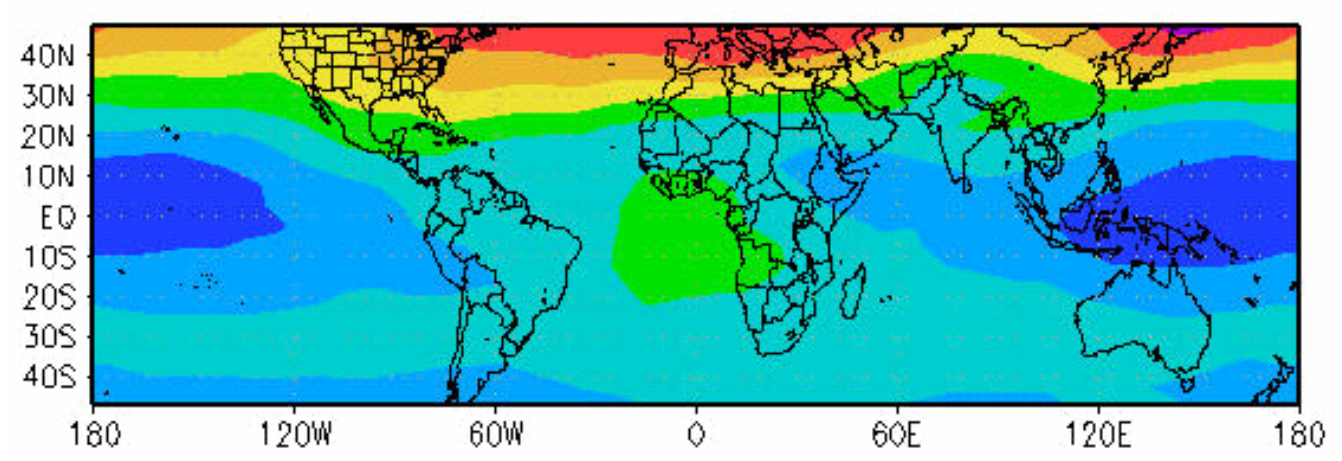

\section{SBUV Tropospheric Ozone Residual (TOR) JJA 1979-91}
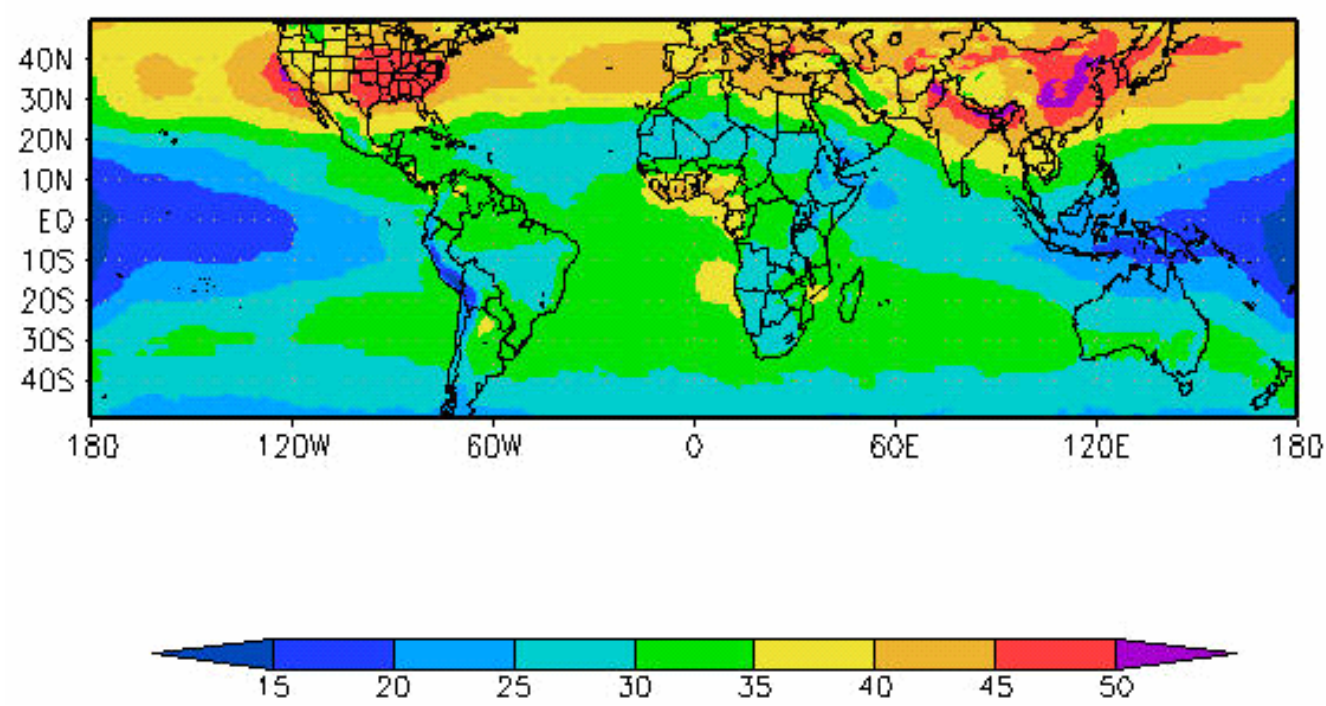

Fig. 2. TOR JJA distribution using the SAGE/TOMS technique described in Fishman and Brackett [1997] (top panel) and TOR calculated using the current technique. Both data sets use available measurements during the same period of time, 1979-1991.

of the satellite data set is used, comparisons with computed TOR values have been found to vary by as much as $\sim 5 \mathrm{DU}$ (Fishman and Brackett, 1997). Previous studies (e.g., Fishman et al., 1990; Hudson and Thompson, 1998; Ziemke et al., 1998; 2000; Fishman and Balok, 1999; Thompson et al., 2003) show good agreement between satellite-derived ozone amounts and integrated ozone derived from ozonesonde measurements. Globally averaged, the TOR value in this study is 31.5 DU. For comparison, the average of the TOMS/SAGE TOR was 32.7 DU in Fishman et al. (1990) and 27.5 DU in Fishman and Brackett (1997), using Version 5 (modified to approximate Version 6) and Version 7 of the TOMS data archive releases, respectively. The current study uses a pre- liminary Version 8 release of the TOMS archive (see discussion in Sect. 2.1; tentative public release date for Version 8 is 2003).

As part of the current study, we compared the stratospheric column ozone amounts using SAGE with the empirically corrected SBUV profiles generated in this study. Using Version 7 of the TOMS archive with the SBUV measurements a globally averaged TOR value of 29.9DU was derived, or $\sim 9 \%$ higher than the TOR when compared with the TOMS/SAGE TOR values when identical sets of TOMS data were used.

The TOMS/SAGE TOR distribution (Fishman et al., 1990) highlighted a number of significant differences between the 


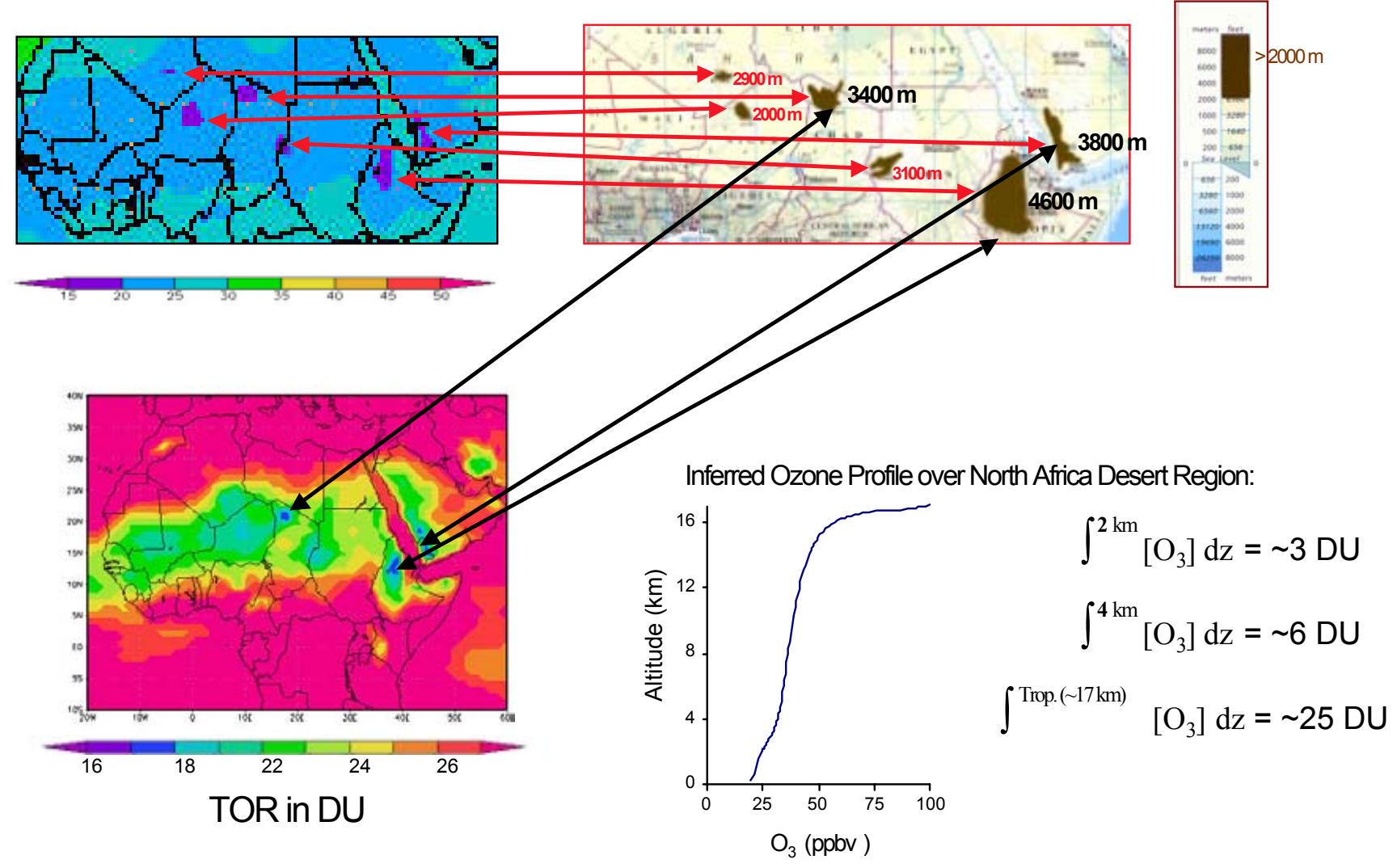

Fig. 3. A series of panels illustrate the relationship between observed TOR during northern hemisphere winter over Sahara region of north Africa and elevated terrain. The upper left panel is an enlargement of the DJF climatological distribution shown in Fig. 1. Areas $<20$ DU (in blue) correspond to the regions on the map indicated by the red arrows where the terrain height is $>2000 \mathrm{~m}$ as indicated by the terrain color scale in the far upper right (from Satellite Atlas of the World, 2001). The lower panel is the same region with enhanced color scale where areas $<17$ DU (in blue) are indicated by black arrows showing elevations $>3400 \mathrm{~m}$. The ozone profile in the lower right depicts the climatological vertical distribution of ozone consistent with the three criteria determined from the altitude-ozone deficits.

seasons and between the two hemispheres. One of the most important findings was that the NH summer shows extensive pollution throughout the middle latitudes. The highest regions appeared to be nonspecific plumes downwind of North America, Europe and Asia. Lowest concentrations were observed over the western tropical Pacific.

In the present TOMS/SBUV seasonal depictions shown in Fig. 1, the regional aspects of these enhancements are significantly better resolved than in the analyses derived using TOMS and SAGE. In the June-July-August (JJA) NH summertime depiction, for example, highest TOR values are located throughout the eastern United States and throughout eastern Asia. Prominent high values are also seen emanating off the west coast of the United States as well as along the Ganges River Valley in northeastern India. Perhaps the largest difference between the TOMS/SAGE and TOMS/SBUV TOR distributions is what is observed over eastern Asia.

Figure 2 shows for comparison the NH summer distribution for the two data sets using only observations from 1979 through 1991 to capture the same period of measurements described in Fishman and Brackett (1997). Considerable detail is now seen over northern India, as well as over central and eastern China, revealing distinct regions of pollution in an area that showed only relatively slightly enhanced levels of TOR in the TOMS/SAGE depiction. In fact, the original TOMS/SAGE TOR over northwest India showed a relative minimum, which was interpreted to be associated with the relatively higher elevations and lack of population in the Tibetan Plateau. The greater detail in the present analysis shows a better-defined, relatively small region of low ozone over the higher elevations. However, just south of that region in the Ganges River Valley, extending west of Delhi and eastward through Bangladesh and northern Burma, much higher values of ozone are observed. High values are now seen throughout central and eastern China.

In the TOMS/SAGE depiction in Fig. 2, the highest TOR values come from the northern reaches of the depiction off the east coast of Asia, whereas this region now shows less of an enhancement although a plume downwind of Asia is 
still evident. The present analysis shows higher values over the landmasses of both the eastern United States and eastern Asia, whereas the older TOMS/SAGE analysis suggested somewhat larger concentrations downwind of these continents rather than over the pollution source regions. Whereas the older analysis indicated high values over all of Europe ( $>45 \mathrm{DU}$ ), the current analysis shows lower values (35 to $45 \mathrm{U})$ over Europe relative to Asia and the United States.

During the same season, another interesting enhancement is found over the south coast of West Africa. In the TOMS/SAGE depiction, a generally elevated region was seen over the Atlantic Ocean. In the current TOMS/SBUV analysis, this region of enhancement is now much better defined over the coastal landmass of the countries of Liberia, Ivory Coast, Ghana, Togo, Benin, and Nigeria where population density is relatively high. Just north of these elevated regions, considerably lower concentrations ( $\sim 25 \mathrm{DU})$ are found over the Sahara Desert. However, the higher land values seen in this area are opposite the land-sea difference observed over most of northern Africa and the subtropical North Atlantic Ocean and the Mediterranean Sea. Over these ocean areas, the TOR values are higher. Such an artifact has been noted as TOMS "GHOST" (global hidden ozone structures from TOMS) values and has been noted by Cuevas et al. (2001). Some evidence of GHOST is also seen off the west coast of Namibia, a feature clearly observed in the TOMS data shown in Fishman et al. (1990), which used Version 5 of the TOMS archive. Most of this artifact was removed in Version 7 (McPeters et al., 1996) when a better cloud algorithm was used to add column ozone amounts in regions where stratus clouds were the dominant cloud type present. The ozone maximum over the South Atlantic off the west coast of Namibia and Angola was shown to be a result of the pollution flowing in the easterlies off of western Africa in combination with the long- range transport from Brazil being carried across the Atlantic after convection elevated the precursors to ozone formation from biomass burning (Fishman et al., 1996). When viewed from the satellite perspective, the higher values were a result of the addition of the two ozone sources being integrated to produce one sustained region of elevated ozone.

In their discussion of GHOST effects, Cuevas et al. (2001) presented only climatological data for the month of July. Because of the seasonality of regional pollution at northern temperate latitudes, sharp delineation along the California coast is a maximum during this time of the year, whereas our TOR analyses show that the land-sea contrast off the coast of Namibia is most enhanced during the biomass burning season of September-October. In the Transport and Atmospheric Chemistry near the EquatorAtlantic (TRACE-A) field campaign, it was shown that the ozone precursors sit off the Namibian west coast and photochemically generate ozone (Fishman et al., 1996), which leads to the SeptemberOctober-November (SON) depiction in Fig. 1 but appears to a lesser extent in the JJA depiction. It would be interesting to see if the GHOST effect exhibits a similar seasonality in this region. Determination of how much land-sea difference observed in TOMS is caused by tropospheric ozone and how much is an artifact of the retrieval process needs to be examined in future studies.

In the SON depiction in Fig. 1, higher values are still seen over the Liberia-to-Nigeria coast and are distinctly separated from the ozone maximum off the Namibian coast. In addition to the broad general maximum observed over the South Atlantic, relatively higher values are also found over the interior of the South American continent and a distinct plume even seems to be emanating from the highly urban Sao PauloRio de Janeiro region. In contrast, there is a well-defined deficit of ozone over the Sahara Desert with the highlands of the desert (northern Chad and northern Niger/southern Algeria) clearly seen in the SON depiction as well as in the December-January-February (DJF) analysis. The higher terrain of the southwestern Arabian Peninsula is coincident with lower TOR values in this region. Another region of interesting difference is the very low values of TOR over western South America defining in much better detail the location of the Andes Mountains. This feature is most noticeable in the March-April-May (MAM) and JJA depictions.

The current TOR for SON shows considerably more detail of the enhancement in the southern subtropics relative to what was observed in the TOMS/SAGE depiction, even though both show distinct enhancements over the southern Indian Ocean stretching to Australia (Fishman et al., 1991). Downwind of southern Africa (i.e., to the east), the transport of pollutants off the coast of South Africa and Madagascar appears to be better defined. A relatively small plume appears to originate from Australia.

In the Northern Hemisphere, some intriguing enhancements are seen that were not previously observed. Over the southern United States, there is a region of enhancement over Texas and Louisiana that did not show up in the TOMS/SAGE TOR. There also seems to be an enhanced region off the California coast, a finding consistent with the modeling study of Stohl et al. (2002), who calculate highest $\mathrm{CO}$ concentrations in the eastern Pacific as a result of anthropogenic emissions and subsequent transport from eastern Asia into this region during this time of the year. Higher amounts of ozone are seen in the extreme eastern North Atlantic just south of the Strait of Gibraltar, which is likewise a GHOST region noted by Cuevas et al. (2001).

In the NH spring months, the most pronounced pollution feature is observable over northeastern India and central China. A plume of elevated ozone across the North Atlantic is also present. At this time of the year an enhancement over west central Africa (Congo, Democratic Republic of the Congo - formerly Zaire, and Gabon) is apparent. Depending on the year, somewhat higher values are also seen over northern Brazil. The very low values over the Andes are well defined in this depiction. 

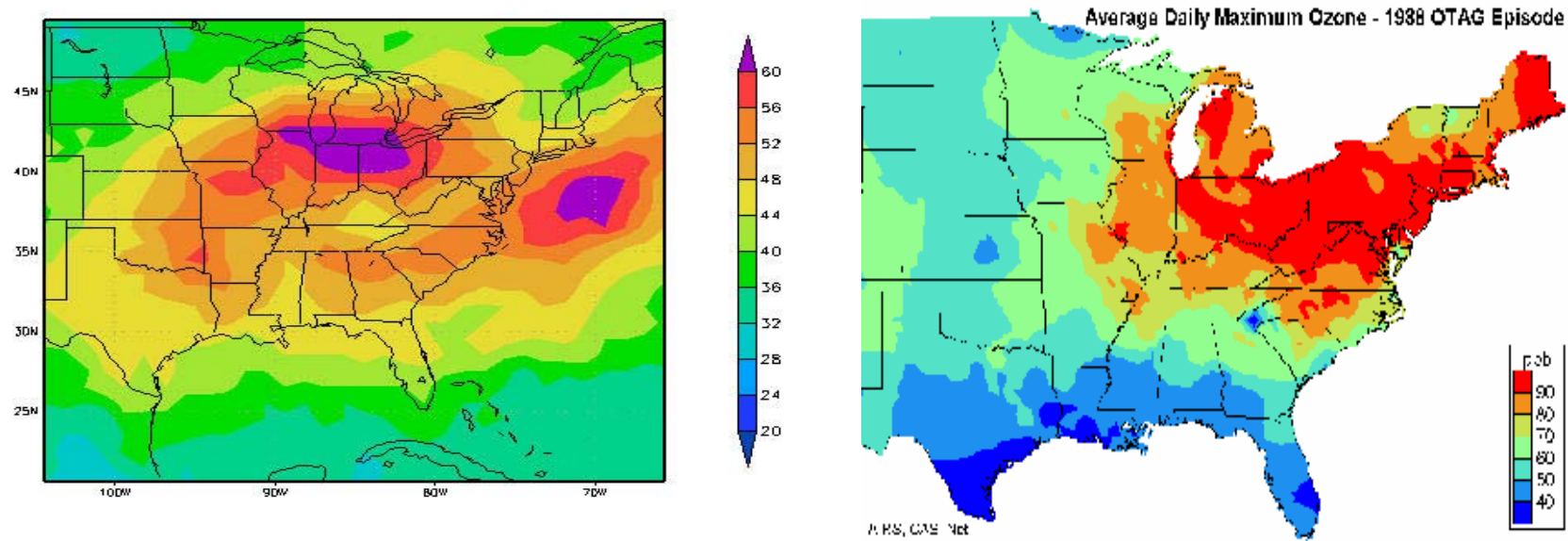

Fig. 4. Distribution of TOR during 2-13 July 1988, and analysis of average daily surface maximum ozone concentration during an air pollution episode over the eastern United States during the same days.

\subsection{Regional Scale Validation}

Fishman et al. (1990) performed a detailed comparison of the TOR with climatological ozonesonde measurements at a number of sites with the conclusion that the satellite method captured the absolute amount, seasonality, and interhemispheric gradient reasonably well. Subsequent validation studies comparing against ozonesondes likewise conclude that the monthly or seasonally averaged amount of tropospheric ozone can be determined to an accuracy of better than 20\% (e.g., Kim and Newchurch, 1996; 1998; Fishman and Brackett, 1997; Ziemke et al, 1998; Thompson and Hudson, 1999); such agreement is not surprising because all these studies use the same TOMS measurements as the starting point to derive the tropospheric component. The data used for comparison in this study use the combined 16-year Nimbus-7 and NOAA-11 ozone profile data set with nearly 3000 ozonesonde measurements from 11 stations. SBUV profiles were required to be within a $5^{\circ}$ latitude by $5^{\circ}$-longitude box around the station location and on the same day as the sounding. The average differences between the empirically corrected TOMS/SBUV TOR and corresponding tropospheric ozone integral constructed from ozonesonde measurements is a $4.0 \mathrm{DU}$ bias, or $\sim 13 \%$, again comparable with all the previous studies cited above.

However, the real strength from the technique presented here is its ability to extract meaningful ozone distributions on a considerably smaller scale than has previously been investigated. Kim and Newchurch $(1996 ; 1998)$ have presented interesting studies over South America and Indonesia examining seasonality and trends over a few specific regions, but the large database presented herein lends itself to regional studies nearly anywhere in the world. One example of this richness is detailed in the depictions shown in Fig. 3. The upper left panel is an enlargement of the December-February climatology shown in Fig. 1. This enlargement over north- ern Africa details the lower values described in the preceding section and compares the location of these lower values with an elevation map of this region shown on the right. At this time of year, locally generated pollution should be minimal and we assume that any regional variations are not a result of local sources. Higher elevations where the altitude is $>2000 \mathrm{~m}$ are shown in a darker shade of brown. The lower left panel is the same data set in the upper left panel but with a much smaller range of colors (10 DU vs. $50 \mathrm{DU})$ that bring out additional detail. In the lower left panel, TOR values $<18 \mathrm{DU}$ are shown in dark blue and correspond to the higher elevated areas in northern Africa ranging between 3400 and $4600 \mathrm{~m}$. Thus, if we assume that the ozone concentration is uniform over the Sahara Desert because there are no inherent sources of pollution, especially during these photochemically inactive months, the following information can be inferred in the lowlands on the fringes of this desert area: A typical TOR value is $\sim 25 \mathrm{DU} ; \sim 6 \mathrm{DU}$ is below $\sim 4000 \mathrm{~m}$; and 2 to $3 \mathrm{DU}$ is below $\sim 2000 \mathrm{~m}$. Unfortunately, there are no ozonesonde measurements in this region, but some measurements at similar latitudes (in India and Hawaii) at the same time of the year suggest that the inferred profile in the lower right portion of the figure is reasonable. This inferred profile could serve as important validation of how sensitive backscatter techniques capture ozone amounts in the lower parts of the atmosphere (Newchurch et al., 2001).

Fishman and Balok (1999) show how the evolution of a regional scale air pollution episode can be inferred from daily TOR maps used in conjunction with meteorological and satellite observations. The relationship between surface ozone concentration and TOR is one that requires considerably more study, but the data sets shown in Fig. 4 (where the left panel shows the TOR distribution during the period 2-13 July 1988, and the right panel depicts the average daily maximum ozone concentrations during the same period) definitely 

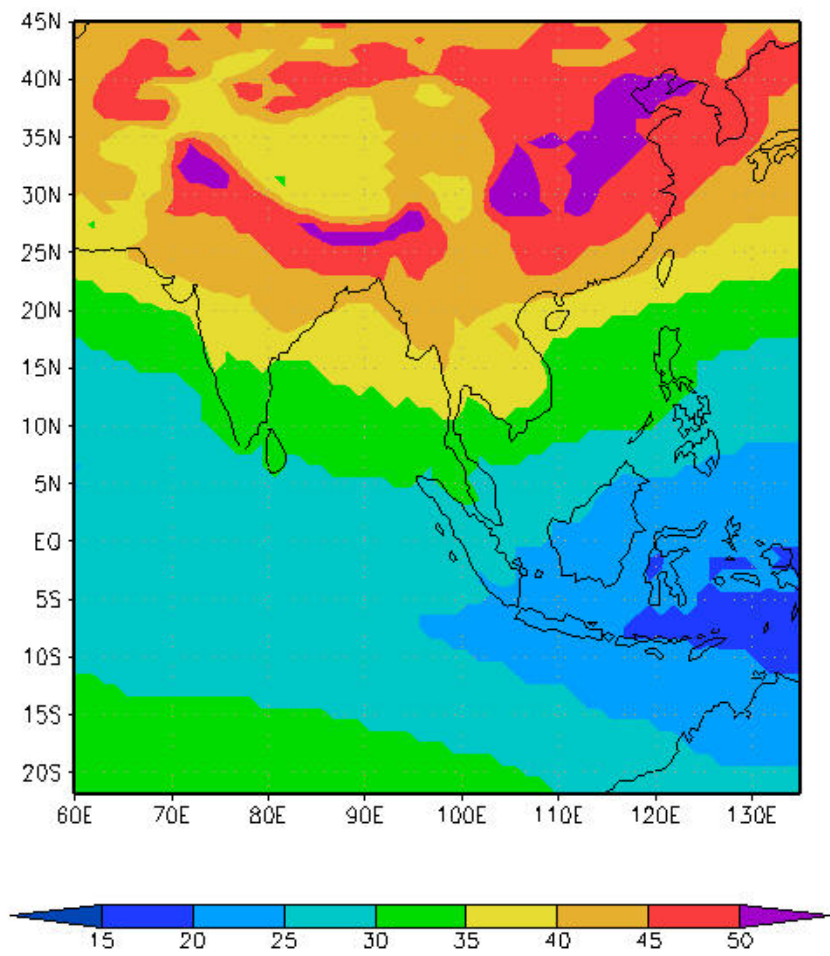

Climatological June-August TOR

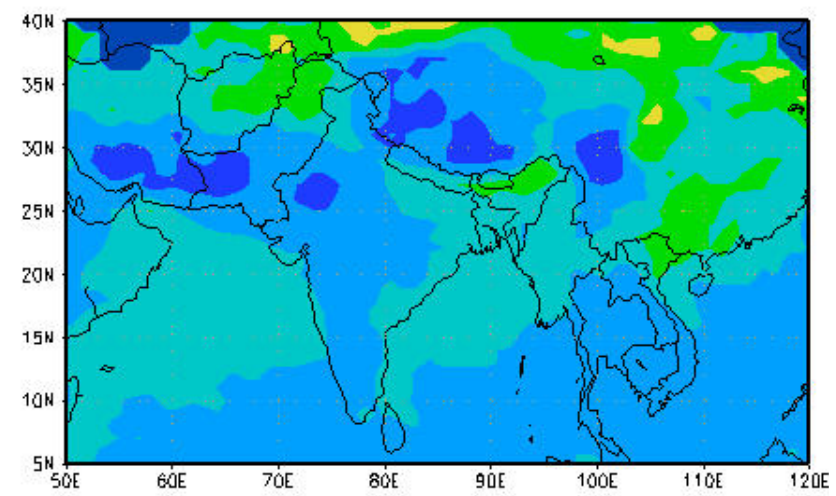

February 1991

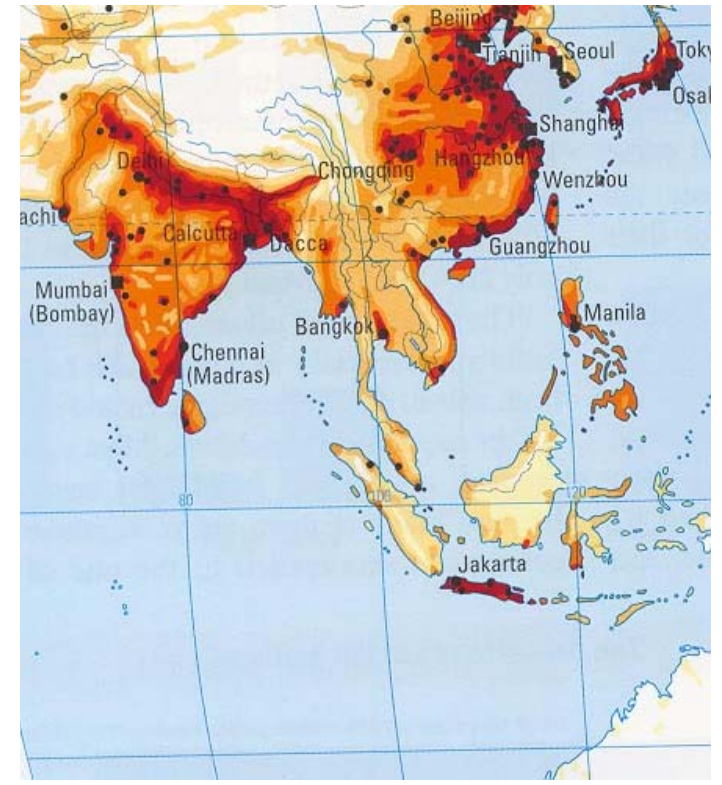

Population Density

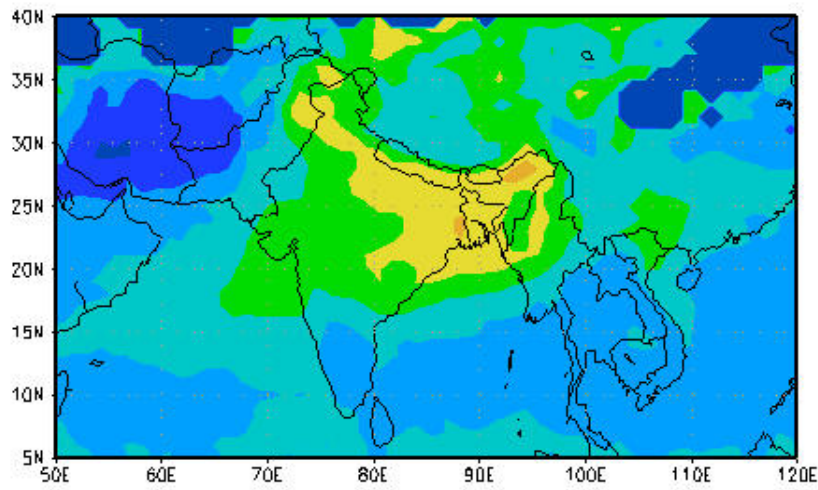

February 1992

Fig. 5. Top two panels illustrate the climatological JJA TOR distribution over India and southeast Asia with the distribution of population density. Bottom two panels illustrate the interannual variability over this region of February 1991 and February 1992.

confirm the strong influence of one upon the other. Fishman et al. (1990) show that both $500 \mathrm{hPa}$ ozone concentrations and TOR values peak during the summer over Wallops Island with values of $\sim 70 \mathrm{ppb}$ and $45 \mathrm{DU}$, respectively. Obviously, the shape of the ozone profile is critical for determining how much integrated ozone is in the tropospheric column, but TOR amounts of $~ 55$ DU (as generally observed over the eastern U.S. in Fig. 4) and average concentrations of $\sim 85$ ppbv that become well mixed throughout a considerable portion of the lower troposphere would be consistent with the relationship found in the Wallops Island ozonesonde data base. Analogously, examining the difference between the areas on either side of the Appalachians with the integrated amount of ozone in the mountains, a deficit of $\sim 8 \mathrm{DU}$ is 
observed. With an altitude difference of $1 \mathrm{~km}$ between the mountains and the surrounding terrain, an average concentration of $\sim 90 \mathrm{ppbv}$ would be calculated, again consistent with the observed maximum concentrations measured at the surface.

Both highest surface and TOR values extend along the northern Midwestern industrial states from Illinois to western Pennsylvania in the east. The TOR is also elevated off the east coast where there are no surface observations; Fishman and Balok (1999) determined that this offshore reservoir of ozone was likely responsible for the subsequent episode that formed over the southern U.S. It should be noted that the surface depiction shown in this analysis was derived from data from more than 500 EPA monitoring stations in the eastern United States. Nowhere else in the world does there exist such a dense ozone monitoring network over such a large area. Without such a dense data network on this scale, validation studies at only a few sites may incorrectly be assumed to be representative of a larger region, when, in fact, such sites can also be controlled by local features, such as local circulation effects and the proximity of nearby sources that result in local measurements being highly dependent on prevailing wind direction.

Figure 5 shows for comparison the summertime TOR with population density maps (Oxford Atlas of the World, 2000) over India, China, and southeast Asia. The similarity between these two distributions is obvious and illustrates how the climatologically high pollution values due to anthropogenic activity are captured by the technique described in the current study. Higher TOR values are observed in every season in these regions and for every year in which data exist. Unlike the surface measurements shown in Fig. 4, there are only a handful of monitoring sites in India (Lal et al., 1998; 2000) and the spatial density is much too sparse to derive any reasonable pattern of the type depicted in Fig. 4.

The much greater data density offered in the current technique allows for accurate depictions of smaller areas of the world to be examined on shorter temporal scales. Whereas Fishman et al. (1990) concentrated on the climatology of TOR and Fishman and Balok (1999) examined a specific case study using daily maps, the data presented in this study highlights the seasonal distribution of specific regions using monthly averages; from such depictions, interannual variability of the TOR fields over a 21-year period (with some data missing between 1993 and 1997) can be discussed. As an example of such interannual variability, Fig. 5 also shows how ozone abundance over northeastern India changed between two consecutive Februarys: 1991 and 1992. The average amount of ozone in this region is $\sim 35 \%$ greater in 1992 than in 1991 (33 DU vs. 25 DU). The presence of a strong El Niño from 1991 to 1993 resulted in the formation of an extensive ridge in the mean tropospheric flow over northern India in January and February 1992 and a relatively high average surface pressure during February 1992 relative to most other years. The relationship between the
El Niño/Southern Oscillation (ENSO) and ozone abundance over this and other regions of the world is part of an ongoing study (Creilson et al., 2002; Fishman et al., 2002), but preliminary analysis suggests that there is a significant relationship between the efficiency of in situ ozone production and the phase of the ENSO cycle. The meteorological conditions brought on by the existence of a strong El Niño may have been conducive to much more ozone production in 1992 than in other years.

\section{Summary and Conclusions}

We have presented a new data set describing the distribution of tropospheric ozone using TOMS and SBUV measurements obtained from 1979 through 2000. Because of the large number of data going into the TOR calculations compared with the earlier amount of data obtained using SAGE and TOMS, smaller scale climatological features are evident that had not been previously noted. Among these features, enhanced ozone distributions over the eastern United States, China, India, and western Africa are observable during NH summer. The previous enhancement observed over the tropical South Atlantic Ocean is distinguishable as separate plumes from southern Africa and South America during the biomass burning season of September and October. Although this study has focused on seasonal and monthly average distributions, daily TOR maps are available between 1979 and 2000 excluding the period from May 1993 through July 1997, primarily because satellites carrying TOMS instruments were not operating. Derivation of daily maps incorporates a five-day average of SBUV measurements to separate the stratospheric component, a feature not desirable when the stratospheric ozone distribution is highly variable on a day-to-day basis. However, the summaries presented in this study have only described one-month averages or longer. On these time scales, the errors potentially caused by daily stratospheric variability (generally not a problem in the tropics and subtropics) cancel each other out because of the high number of measurements that comprise these monthly averages.

The planned launch of the Ozone Monitoring Instrument (OMI) aboard NASA Earth Observing System's Aura in 2004 (see http://eos-chem.gsfc.nasa.gov/) will provide a total ozone data product similar to TOMS, but with a horizontal footprint as small as $13 \mathrm{~km}$ by $24 \mathrm{~km}$ at nadir to $\sim 100 \mathrm{~km}$ at the extreme off-nadir portion of the orbital track. This capability will allow for much higher resolution information to be obtained. With the stratospheric measurement capabilities of other Aura instruments taking measurements at the same time (HIRDLS: High Resolution Dynamic Limb Sounder; and MLS: Microwave Limb Sounder), the concurrent SCO distribution should be much better than the current SBUV five-day average used in the present study. Thus, the ability to resolve regional information from satellite measurements 


\section{Calculation of TOMS/SBUV Tropospheric Ozone Residual}

\section{Part I: Calculate Stratospheric Column Ozone (SCO)}

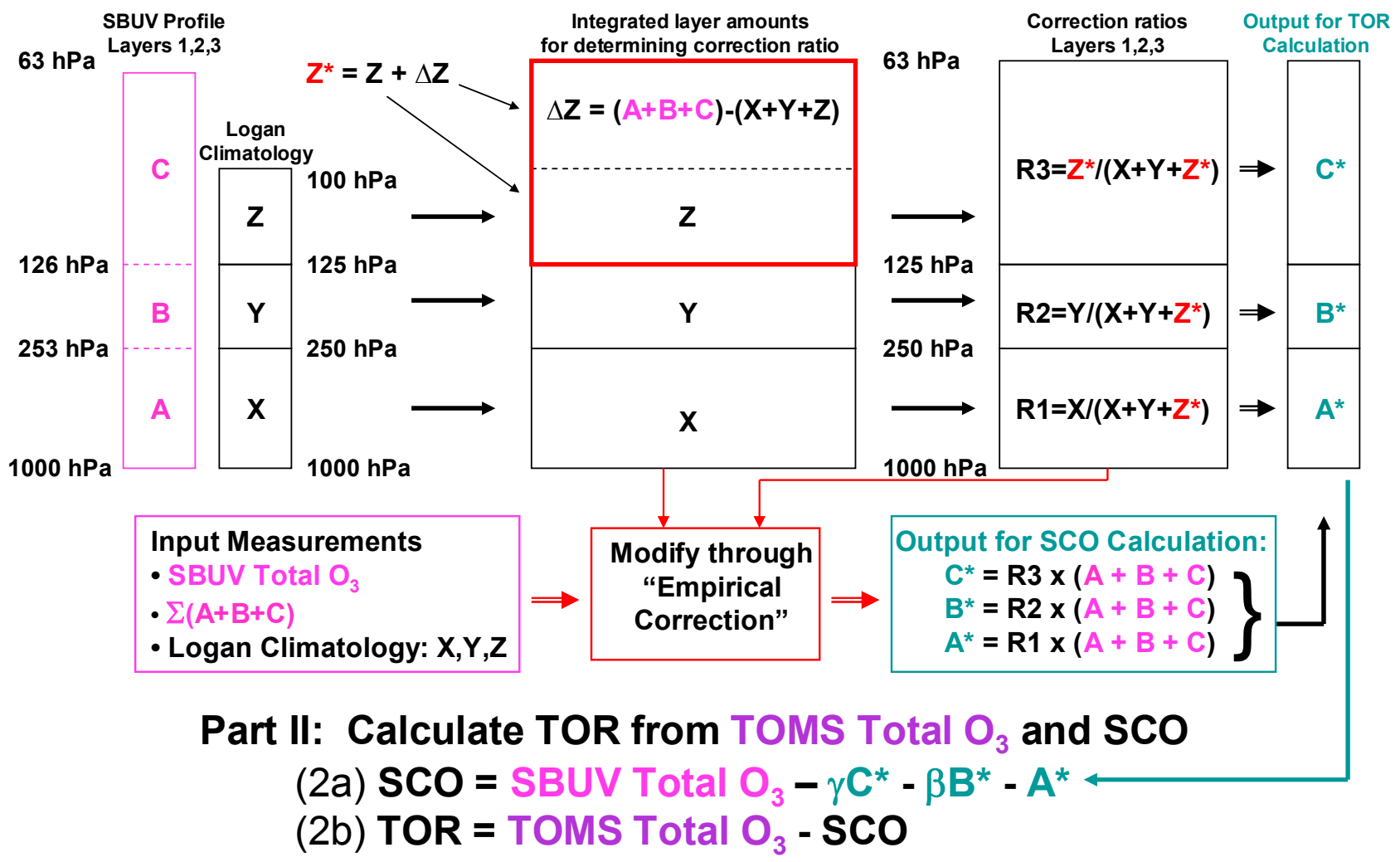

Note: $\gamma$ and $\beta$ are values between 0 and 1 and are determined by NCEP/NCAR Reanalysis tropopause height

Fig. 6. Schematic diagram showing how the TOR data are calculated from TOMS and SBUV measurements using the empirical correction technique. See text for explanation.

should be improved considerably due to the availability of these future capabilities. The data set described in this study (http://asd-www.larc.nasa.gov/TOR/data.html) will ideally serve as a prototype of the type of information that will be available as the above new instruments become operational. In addition, future instruments (e.g., the Tropospheric Emission Spectrometer, TES, http://eos-chem.gsfc.nasa. gov/instruments/tes/introduction.html on the Aura satellite and the Infrared Atmospheric Sounding Interferometer, IASI, http://www.esa.int/export/esaME/iasi.html on the operational meteorological European satellite) will provide direct measurements of tropospheric ozone against which the technique described here can be validated. Finally, as is the case with all satellite data sets, ongoing efforts are being carried out to ensure this data set's accuracy and utility. Metadata is being developed so that the user is made aware of the caveats for specific observations when screening criteria are invoked (see Fishman et al., 1990). Certainly, the quality of the data will improve as we understand the operational deficiencies of the current instruments, but most importantly, as new capabilities become a reality with the launch of future satellites.

\section{Appendix A}

Description of empirically corrected modified residual method

The derivation of the TOR is a two-step process (see Fig. 6). First, the empirically corrected stratospheric column ozone (SCO) is calculated using three inputs:

1. Total $\mathrm{O}_{3}$ column from $\mathrm{SBUV}$;

2. The integral of ozone layer amounts in three lowest layers, $\sum[\mathrm{A}+\mathrm{B}+\mathrm{C}]$, from SBUV; and 


\section{Logan Tropospheric Ozone Climatology - JULY}

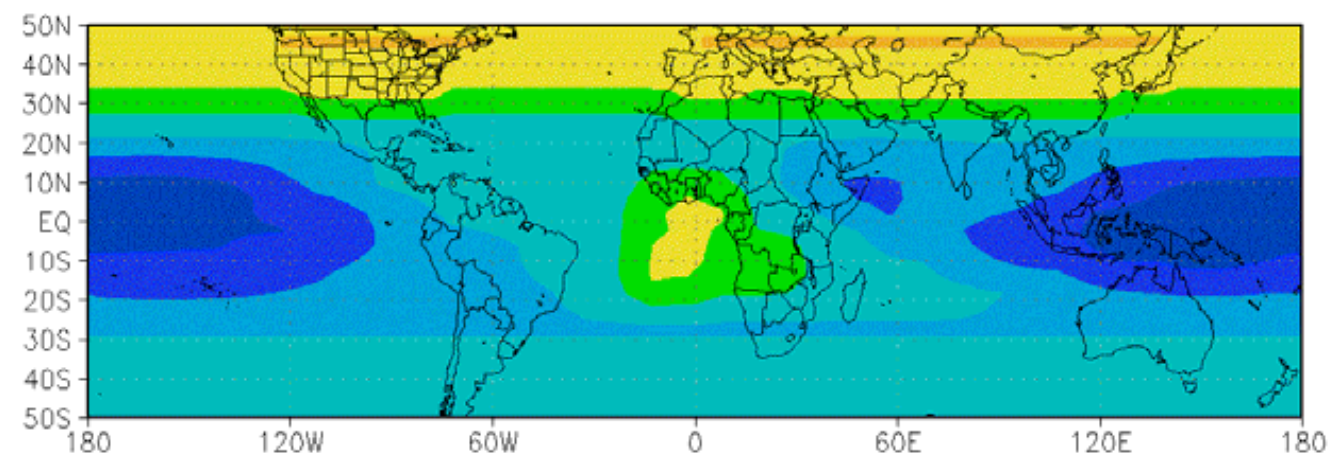

SBUV Tropospheric Ozone Residual (TOR) Climatology - JULY
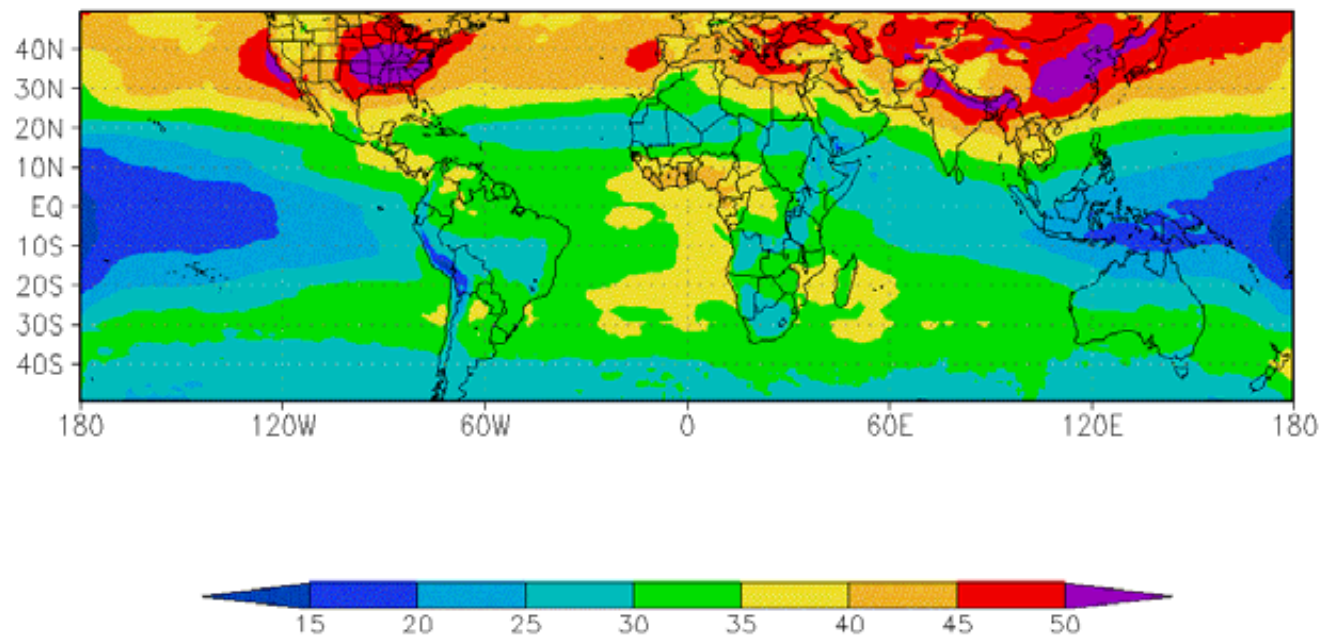

Fig. 7. Comparison of integrated tropospheric ozone from the surface to $250 \mathrm{hPa}$ derived from Logan (1999) during July (top panel) with the July TOR climatology using the present technique.

3. the Logan (1999) climatological tropospheric ozone distribution between the surface and $100 \mathrm{hPa}$ (partitioned into sub-layers $\mathrm{X}, \mathrm{Y}$, and $\mathrm{Z}$ ).

The initial part of this procedure is extending the Logan climatology to a pressure level of $63 \mathrm{hPa}$ which is done by assuming that the sum of the ozone in the three layers from the SBUV measurements is correct (Fishman and Balok, 1999); this extension yields the new integrated layer values $\mathrm{X}, \mathrm{Y}$, and $Z^{*}$. The next step is to generate a new ratio for each of the three layers $\mathrm{A}, \mathrm{B}$, and $\mathrm{C}$ to the sum of the three layers $\left(\sum[A+B+C]\right)$. These three ratios, $R 1, R 2$, and $R 3$, are derived from a knowledge of the Logan climatology. The product of the two numbers results in the new quantities $\mathrm{A}^{*}$, $\mathrm{B}^{*}$ and $\mathrm{C}^{*}$, which are then used in the calculation of SCO.

To calculate the SCO, we must also know the height of the tropopause, which is obtained from the archived NCEP/NCAR reanalysis, and the fraction of either layer B or $\mathrm{C}$ that is defined as tropospheric. If the tropopause height does not lie fall within Layers B and C, the SCO is not calculated. If the height of the tropopause $\left(\mathrm{z}_{\text {trop }}\right)$ is above $126 \mathrm{hPa}$ (i.e., within Layer C), then all of Layer B is in the troposphere and the fractional coefficient, $\beta$, is one; if $\mathrm{z}_{\text {trop }}$ is within Layer B, then Layer C is entirely stratospheric and $\gamma$ equals zero.

The SCO can now be computed (Eq. 2a) and then subtracted from the TOMS total ozone value to derive the TOR (Eq. 2b). Thus, the only measurement information from SBUV is $\sum[\mathrm{A}+\mathrm{B}+\mathrm{C}]$ and the total column from SBUV. The original archived values of the three lowest levels (A, $\mathrm{B}$, and $\mathrm{C}$ ) are never used to derive the TOR. Because the data density of SBUV is relatively sparse (compared with TOMS), five days of SCO values are used to derive the SCO field for the central day of that 5-day period. The SCO field is still relatively smooth and the spatial density of the TOR field is determined from the data density of the TOMS data used for that day. The measurements are never constrained 

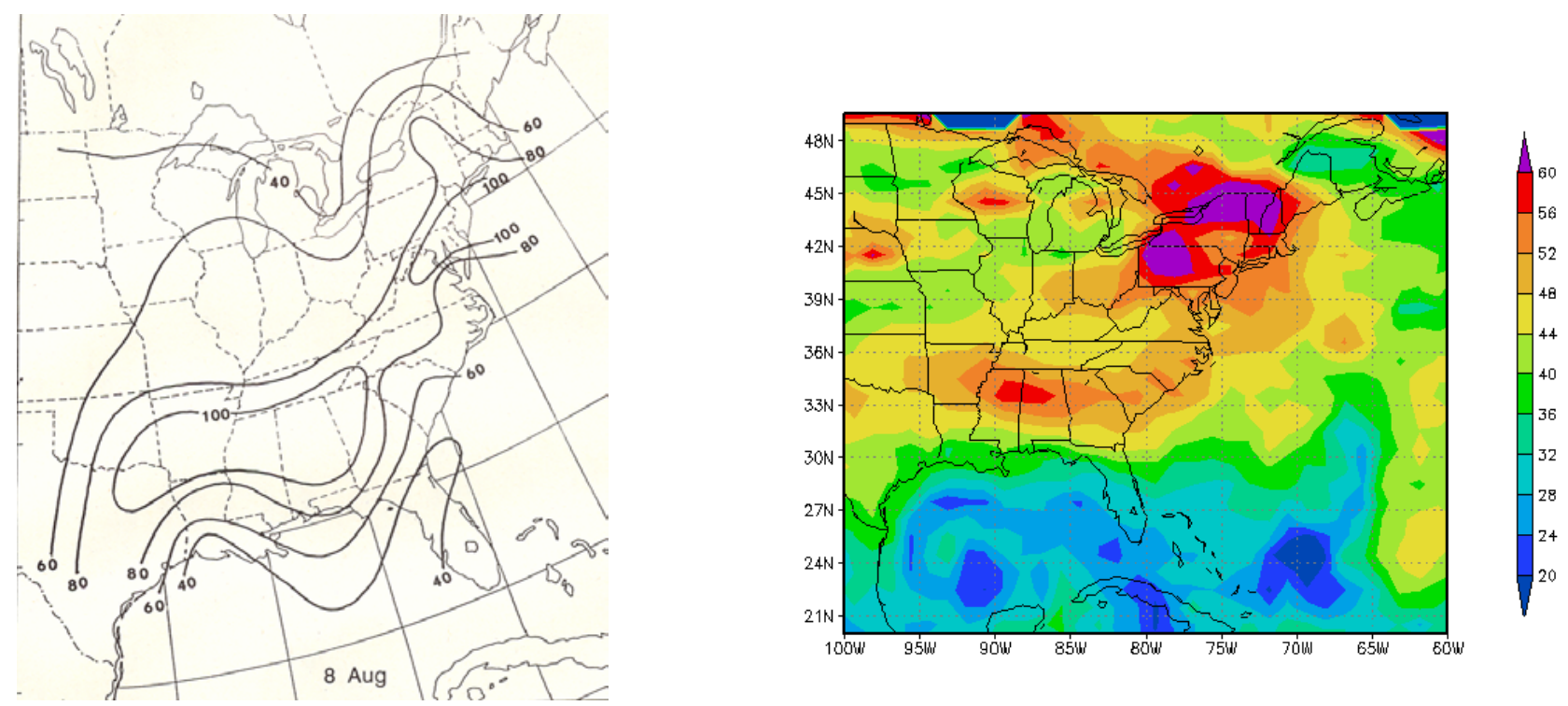

Fig. 8. The distribution of surface ozone (left panel) and the TOR (right panel) for 8 August 1980 are shown. High surface ozone and TOR values are evident over much of the southern U.S. on this date. For the error analysis, the assumption is made that the stratospheric component of the total ozone field is fixed at $248 \mathrm{DU}$ along $35^{\circ} \mathrm{N}$ latitude line.

by the Logan climatology and there is no reason to assume that Logan's product and the TOR fields we produce are the same. This finding is borne out by the data product displayed in Fig. 7 where the SBUV/TOMS TOR is compared with the Logan July $1000 \mathrm{hPa}-250 \mathrm{hPa}$ integrated ozone climatology. The ozone distribution at middle latitudes in the Northern Hemisphere is nearly zonal in the Logan depiction and none of the regional enhancements highlighted and discussed in the current study are present.

\section{Appendix B}

\section{Error analysis of empirical correction method}

In this section, we present a discussion that provides insight into the accuracy of the technique discussed on the preceding pages. The TOR data described in this study are quantities that are difficult to compare since comparable measurements must be derived from other techniques, such as from ozonesonde or aircraft profile measurements or from lidar measurements that derive tropospheric column ozone (TCO) integrals throughout the entire troposphere. As stated in the main part of the paper, climatological ozonesonde comparisons show agreement to within $\sim 13 \%$.

However, the primary breakthrough and focus in this study is the assertion that the empirical correction method has yielded a wealth of information that, for the first time, shows the regional aspect of air pollution from satellite data products. This Appendix will focus on the accuracy of this method by comparing it to an idealized case study based on available data sets. Fishman et al. (1987) first described the possibility that a pollution episode could be seen in the TOMS total ozone data (see Fig. 8). We use that 1980 case study to examine the accuracy of the empirical correction since it is one of the few data sets that have surface and aircraft measurement to confirm that enhanced levels of satellite-derived TOR are consistent with these other types of data sets.

The essence of this error analysis is to examine how accurately the regional variability of our technique is captured. Using the formulation described in Appendix A, we set up a scenario for our error analysis using data based on the 8 August 1980, ozone pollution episode over the southern and eastern United States. This widespread pollution event is seen in the surface EPA observations in the southern U.S. and an enhancement over western Pennsylvania has been captured by aircraft measurements as part of the PEPE/NEROS (Persistent Elevated Pollution Episode/Northeast Regional Oxidant Study) field campaign (Fishman et al., 1985).

To assess the error introduced by the empirical method on the calculated TOR, some assumptions must be postulated that are not rigorously true, but are nonetheless reasonable in this case so that the errors in the methodology can be quantified. First, we assume that the stratospheric column ozone integral (SCO) and the height of the tropopause do not change longitudinally (i.e., in the east-west direction) for $\sim 5000 \mathrm{~km}$ (41 gridded TOMS data points). Thus, for our ground truth, we assume that the only change in the amount of ozone in the total column as a function of longitude is the amount of change of ozone in the troposphere. Working from 


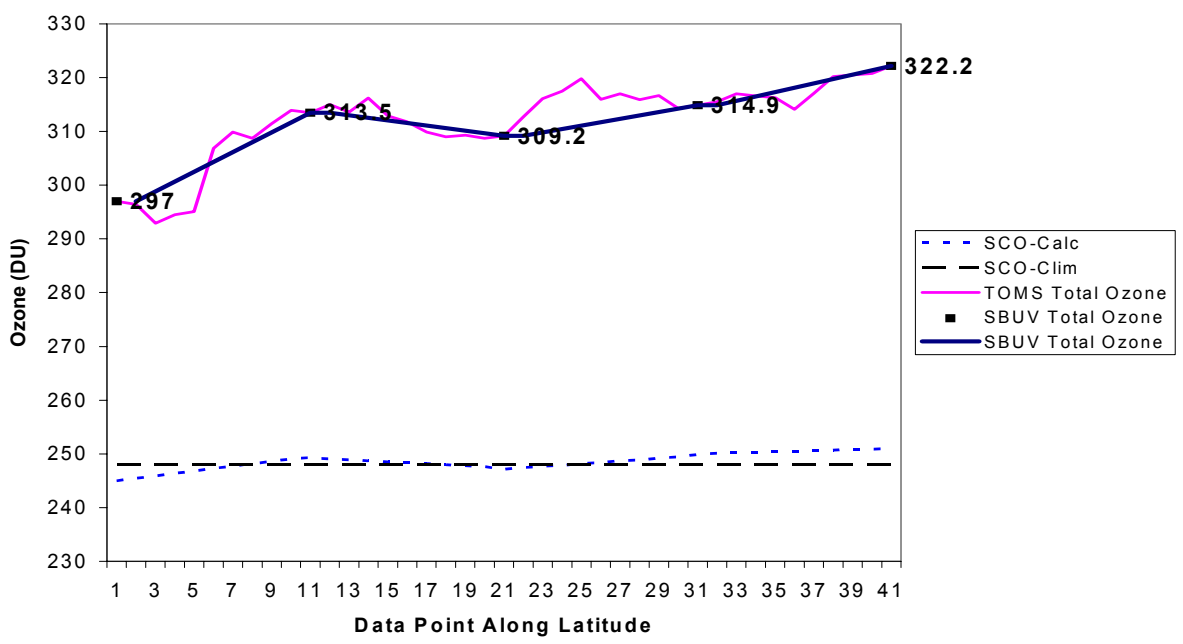

Fig. 9. The TOMS and SBUV total ozone values as a function of data point ( 1 to 41 ) along the $35^{\circ} \mathrm{N}$ parallel are plotted as the heavy blue lines and thin red lines in the upper part of the graph. The dashed blue line is the calculated stratospheric column ozone (SCO) calculated using the empirical correction described in Appendix A. For reference, the 248-DU line is also shown in this figure and represents the assumed SCO for this example.

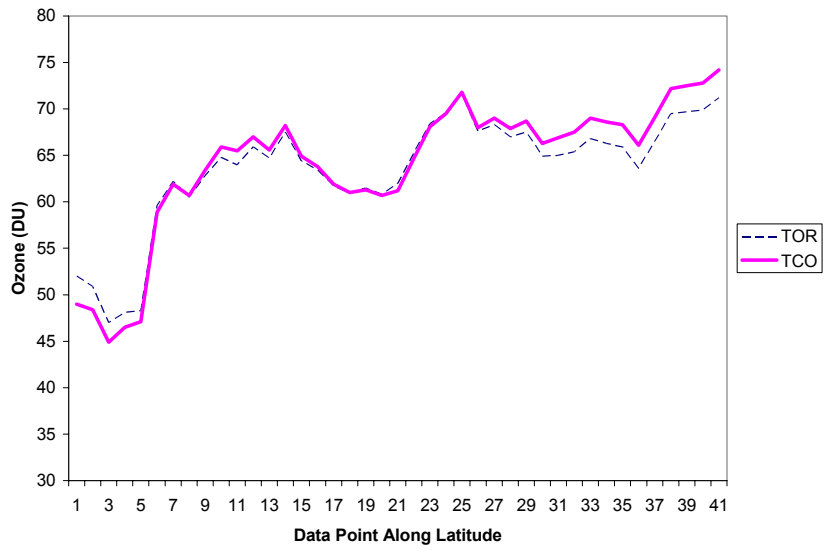

Fig. 10. Calculated TOR (blue line) using the empirical correction is compared with idealized TCO values depicted as the red line.

west to east (point 1 to point 41 in our TOMS matrix; see Fig. 9), we assume that the westernmost point is characteristic of the climatological amount of ozone between the surface and $113 \mathrm{hPa}, 49 \mathrm{DU}$, at this time of the year at this latitude (Logan, 1999). The tropopause is fixed at $113 \mathrm{hPa}$ (corresponding to $\gamma=0.21$; refer to Appendix A) and the SCO is assumed constant at $248 \mathrm{DU}$ (since the TOMS value at that same location is $297 \mathrm{DU})$. In actuality, the stratospheric ozone from SBUV above $63 \mathrm{hPa}$ exhibited a range of $8 \mathrm{DU}$ from 223 DU to 231 DU over the 3-day period 7-9 August whereas the TOMS total ozone along the $35^{\circ} \mathrm{N}$ parallel exhibited a range of $30 \mathrm{DU}$ from a low value of $293 \mathrm{DU}$ to a high value of $323 \mathrm{DU}$ over the same longitude range on 8 August.
Next, for this specific analysis, we assume that we have an independent SBUV measurement every $\sim 1250 \mathrm{~km}$ (every 10th TOMS data point) giving us independent information about the total ozone column and the sum of the lowest three layers $(A+B+C$ in Fig. 6). In this particular example, the five SBUV total ozone amounts are 297.0, 313.5, 309.2, 314.9, and 322.2 DU (see Fig. 9) and the integrals in the lowest three layers are 74.0, 90.5, 86.2, 92.0, and 99.2 DU; after the empirical correction, the calculated SCO values are 245.0, $249.3,247.2,249.9$, and 251.0 DU and the SCO values at the intermittent gridded TOMS locations are simply linearly interpolated between these five values. Recalling that we have assumed that the SCO is ideally fixed (for this example) at 248 DU, then the error in the SCO column is 3 DU or less at any of the five locations. This error then translates directly into the difference between the calculated TOR and our "assumed-to-be correct" TCO quantity. These two quantities are plotted as function of longitude (matrix data point) in Fig. 10 and the differences between them are what we call the "error" in this analysis.

Examination of Fig. 10 shows that, the shorter scale variability of the TOMS total ozone is preserved in the TOR calculations using the empirical correction technique. The difference between the two quantities is less than $3 \mathrm{DU}$ at every point and the gradient in the TOR is muted relative to the gradient in the actual TCO. For this idealized situation, the difference between the highest and lowest TCO is 29.3 DU whereas the empirical correction shows a difference of $24.2 \mathrm{DU}$, or in other words, $\sim 83 \%$ of the enhancement during this pollution episode is observed. This analysis is independent of how efficiently TOMS captures the amount of ozone in the lowest part of the troposphere. If there existed an actual set of measurements that compared the TOR with the 
integrated amount of ozone in the troposphere, and if TOMS did not "measure" all of the ozone present in the lowest part of the troposphere, the $83 \%$ value would represent an upper limit on the accuracy of the empirical correction methodology to observe tropospheric ozone. Nonetheless, we believe that this analysis is a fair assessment that demonstrates this technique's ability to capture regional features, even if we must also conclude that the magnitude of regional episodes will be underestimated.

Acknowledgements. We thank Brad Pierce of NASA Langley for his comments on an earlier version of this manuscript; we also appreciate the Interactive Comments of those who participated in the ACPD portion of this paper. Collectively, these suggestions resulted in a considerably improved article. This work has been supported through NASA's Atmospheric Chemistry Modeling and Analysis Program.

\section{References}

Bhartia, P. K., McPeters, R. D., Mateer, C. L., Flynn, L. E., and Wellemeyer, C.: Algorithm for the estimation of vertical ozone profiles from the backscattered ultraviolet technique, J. Geophys. Res., 101, 18 793-18 806, 1996.

Creilson, J. K., Fishman, J., and Balok, A. E.: Intercontinental transport of tropospheric ozone: A study of its seasonal transport and variability across the North Atlantic utilizing tropospheric ozone residuals, presented at IGAC/CACGP Scientific Conference, Crete, Greece, 2002.

Cuevas, E., Gill, M., Rodriguez, J., Navarro, M., and Hoinka, K. P.: Sea-land total ozone differences from TOMS: GHOST effect, J. Geophys. Res., 106, 27 645-27 755, 2001.

Fishman, J. and Balok, A. E.: Calculation of daily tropospheric ozone residuals using TOMS and empirically improved SBUV measurements: Application to an ozone pollution episode over the eastern United States, J. Geophys. Res., 104, 30319-30 340, 1999.

Fishman, J. and Brackett, V. G.: The climatological distribution of tropospheric ozone derived from satellite measurements using Version 7 TOMS and SAGE data sets, J. Geophys. Res, 102, 19275-19278, 1997.

Fishman, J., Vukovich, F. M., and Browell, E. V.: The photochemistry of synoptic-scale ozone synthesis: Implications for the global tropospheric ozone budget, J. Atmos. Chem., 3, 299-320, 1985.

Fishman, J., Vukovich, F. M., Cahoon, D. R., and Shipham, M. C.: The characterization of an air pollution episode using satellite total ozone measurements, J. Clim. Appl. Meteorol., 26, 16381654, 1987.

Fishman, J., Watson, C. E., Larsen, J. C., and Logan, J. A.: Distribution of tropospheric ozone determined from satellite data, J. Geophys. Res, 95, 3599-3617, 1990.

Fishman, J., Fakhruzzaman, K., Cros, B., and Nganga, D.: Identification of widespread pollution in the southern hemisphere deduced from satellite analyses, Science, 252, 1693-1696, 1991.

Fishman, J., Hoell Jr., J. M., Bendura, R. D., McNeal, R. J., and Kirchhoff, V. W. J. H.: NASA GTE TRACE-A experiment
(September-October 1992): Overview, J. Geophys. Res., 101, 23 865-23 879, 1996.

Fishman, J., Creilson, J. K., and Balok, A. E.: Interannual variability of regional enhancements of tropospheric ozone determined from two decades of satellite observations, to be presented at 34th Scientific Assembly, Committee on Space Research (COSPAR), Houston, TX, 2002.

Heath, D. F., Krueger, A. J., Roeder, H. A., and Henderson, B. D.: The solar backscatter ultraviolet and total ozone spectrometer (TOMS/SBUV) for Nimbus G, Opt. Eng., 14, 323-331, 1975.

Hudson, R. D. and Thompson, A. M.: Tropical tropospheric ozone from total ozone mapping spectrometer by a modified residual method, J. Geophys. Res., 103, 22 129-22 145, 1998.

Jiang, Y. and Yung, Y. L.: Concentrations of tropospheric ozone from 1979 to 1992 over tropical Pacific South America from TOMS data, Science, 272, 745-748, 1996.

Kalnay, E., et al.: The NCEP/NCAR 40-year reanalysis project, Bull. Amer. Met. Soc., 77, 437-472, 1996.

Kim, J. H. and Newchurch, M. J.: Climatology and trends of tropospheric ozone over the eastern Pacific Ocean: The influences of biomass burning and tropospheric dynamics, Geophys. Res. Lett., 23, 3723-3726, 1996.

Kim, J. H. and Newchurch, M. J.: Biomass-burning influence on tropospheric ozone over New Guinea and South America, J. Geophys. Res., 103, 1455-1461, 1998.

Lal, S., Naja, M., and Jayaraman, A.: Ozone in the marine boundary layer over the tropical Indian Ocean, J. Geophys. Res., 103, 18 907-18 917, 1998.

Lal, S., Naja, M., and Subbaraya, B. H.: Seasonal variations in surface ozone and its precursors over an urban site in India, Atmos. Env., 34, 2713-2724, 2000.

Logan, J. A.: An analysis of ozonesonde data for the troposphere: Recommendations for testing 3-D models, and development of a gridded climatology for tropospheric ozone, J. Geophys. Res., 104, 16 115-16 149, 1999.

McPeters, R. D., Krueger, A. J., Bhartia, P. K., Herman, J. R., Oakes, A., Ahmad, Z., Cebula, R. P., Schlesinger, B. M., Swissler, T., Taylor, S. L., Torres, O., and Wellemeyer, C. G.: Nimbus 7 Total Ozone Mapping Spectrometer (TOMS) data products user's guide, NASA RP-1323, Natl. Aeronaut. and Space Admin., Greenbelt, Md., 85 pp., 1993.

McPeters, R. D., Bhartia, P. K., Krueger, A. J., Herman, J. R., Schlesinger, B. M., Wellemeyer, C. G., Seftor, C. J., Jaross, G., Taylor, S. L., Swissler, T., Torres, O., Labow, G., Byerly, W., and Cebula, R. P.: Nimbus 7 Total Ozone Mapping Spectrometer (TOMS) data products user's guide, NASA RP-1384, Natl. Aeronaut. and Space Admin., Greenbelt, Md., 67 pp., 1996.

Newchurch, M. J., Liu, X., and Kim, J. H.: Lower-tropospheric ozone (LTO) derived from TOMS near mountainous regions, J. Geophys. Res, 106, 20 403-20 412, 2001.

Oxford Atlas of the World (8th Edition), Oxford University Press, New York, 304 pp., 2000.

Satellite Atlas of the World, Helicon Publ., Oxford, U.K., 224 pp., 2001.

Stohl, A., Eckhardt, S., Forster, C., James, P., and Spichtinger, N.: On the pathways and timescales of intercontinental air pollution transport, J. Geophys. Res., 107(D23), 4684, doi:10.1029/2001JD001396, 2002. 
Thompson, A. M. and Hudson, R. D.: Tropical tropospheric ozone (TTO) maps from Nimbus 7 and Earth Probe TOMS by the modified-residual method: Evaluation with sondes, ENSO signals, and trends from Atlantic regional time series, J. Geophys. Res., 104, 26961-26975, 1999.

Thompson, A. M., Witte, J. C., McPeters, R. D., Oltmans, S. J., Schmidlin, F. J., Logan, J. A., Fujiwara, M., Kirchhoff, V. W. J. H., Posny, F., Coetzee, G. J. R., Hoegger, B., Kawakami, S., Ogawa, T., Johnson, B. J., Vömel, H., and Labow, G.: Southern Hemisphere Additional Ozonesondes (SHADOZ) 1998-2000 tropical ozone climatology 1. Comparison with Total Ozone Mapping Spectrometer (TOMS) and ground-based measurements, J. Geophys. Res., Vol. 108, 8238, doi: 10.1029/2001JD000967, 2003.

Torres, O. and Bhartia, P. K.: Impact of tropospheric aerosol absorption on ozone retrieval from backscattered ultraviolet measurements, J. Geophys. Res., 104, 21 569-21 577, 1999.
WMO (World Meteorological Organization): SPARC/IOC/GAW Assessment of Trends in the Vertical Distribution of Ozone, N. Harris, R. Hudson, and C. Phillips (Eds), SPARC Report no. 1, World Meteorological Organization Global Ozone Research and Monitoring ProjectReport No. 43, Geneva, 1998.

Ziemke, J. R., Chandra, S., and Bhartia, P. K.: Two new methods for deriving tropospheric column ozone from TOMS measurements: Assimilated UARS MLS/HALOE and convective-cloud differential methods, J. Geophys. Res., 103, 22 115-22 127, 1998.

Ziemke, J. R., Chandra, S., and Bhartia, P. K.: A new NASA data product: Tropospheric and stratospheric column ozone in the tropics derived from TOMS measurements, Bull. Amer. Meteorol. Soc., 81, 580-583, 2000. 